\title{
Interaction of Rhodium with Chloro-Complexes of Palladium at Elevated Temperatures
}

\author{
Oleg V. Belousov ${ }^{a^{*}}$ and Natalya V. Belousova ${ }^{b}$ \\ anstitute of Chemistry and Chemical Technology SB RAS \\ 50/24 Akademgorodok, Krasnoyarsk, 660036, Russia \\ ${ }^{b}$ Siberian Federal University \\ 79 Svobodny, Krasnoyarsk, 660041, Russia
}

Received 11.02.2015, received in revised form 30.03.2015, accepted 19.05.2015

Powders of superfine rhodium with mono- and polyblock structures were obtained. The processes of coarsening of nanodispersed rhodium crystallites were investigated in detail at 130 and $180{ }^{\circ} \mathrm{C}$. In muriatic solutions, dissolution of metal rhodium was found to occur. It was connected with the presence of chemisorbed oxygen at its surface. The possibility of formation of rhodium-palladium substitutional solid solutions on the electrolytic precipitation was firstly established.

Keywords: autoclave technologies, rhodium, palladium, metal nanoparticles, substitutional solid solutions.

\section{Взаимодействие родия с хлорокомплексами палладия при повышенных температурах}

\author{
О.В. Белоусов ${ }^{a}$ Н.В. Белоусова ${ }^{\sigma}$ \\ ${ }^{a}$ Институт химии и химической технологии СО РАН \\ Россия, 660036, Красноярск, Академгородок, 50/24 \\ ${ }^{6}$ Сибирский федеральный университет \\ Россия, 660041, Красноярск, Свободный, 79
}

Синтезированы порошки высокодисперсного родия моно- $и$ полиблочной структуры. Исследованы прочессы укрупнения кристаллитов нанодисперсного родия. Методами электронной просвечивающей микроскопии и рентгенофазового анализа детально изучен процесс укрупнения родиевой черни при 130 и $180{ }^{\circ} \mathrm{C}$. Установлено, что в растворах соляной кислоты наблюдается растворение родия (0), связанное с наличием на его поверхности хемосорбированного кислорода. Впервые показана возможность образования твердых родийпалладиевых растворов замещения при протекании реакиии цементации.

Ключевые слова: автоклавные технологии, родий, палладий, металлические наночастицы, твердые растворы замещения.

(C) Siberian Federal University. All rights reserved

* Corresponding author E-mail address: ov_bel@icct.ru 


\section{Введение}

В последнее время интенсивное развитие исследований в области методов синтеза би- и полиметаллических частиц привело к появлению новых материалов, которые нашли широкое применение в самых различных областях, таких как гетерогенный катализ, водородная энергетика, электроника, электротехника, фармацевтика, медицина и биология. В ряде случаев, например в катализе, биметаллические наночастицы более эффективны по сравнению с их монометаллическими аналогами. Более высокая эффективность катализаторов на основе биметаллических наночастиц проявляется в более высокой степени селективности и синергетичном поведении компонентов таких систем.

Биметаллические наночастицы на основе родия и палладия находят свое применение в качестве компонентов автомобильных катализаторов для нейтрализации выхлопных газов. $\mathrm{Rh}$-Pd биметаллические катализаторы более активны в реакциях окисления СО по сравнению с аналогичными монометаллическими катализаторами в идентичных реакционных условиях благодаря повышенной способности родия расщеплять $\mathrm{O}_{2}$ и тенденции палладия избирательно связывать СО [1].

Кроме того, катализаторы на основе родия часто используют в реакциях гидрирования аренов [2]. В частности, родий-палладиевые катализаторы показали себя весьма эффективно в реакции гидрирования бензола при комнатных температурах по сравнению с различными монометаллическими катализаторами на основе благородных металлов [3]. Это лишь некоторые примеры применения биметаллических наночастиц Rh-Pd.

Структура Rh-Pd наночастиц зависит главным образом от метода их получения. Согласно диаграмме состояния в системе родий-палладий возможно образование ряда твердых растворов [4]. В работе [5] предложен интересный подход к получению твердых родий-палладиевых растворов замещения при помощи восстановительного термолиза. При восстановлении из растворов некоторые авторы получали механическую смесь индивидуальных компонентов $[6,7]$. В частности, в работе [6] биметаллические наночастицы Rh-Pd синтезированы методом одновременного восстановления двух прекурсоров в среде аргона при использовании поли(винилпирролидона) в качестве ПАВ. Полученные частицы, размер которых составлял около 15 нм, представляли собой частицы со структурой «ядро-оболочка»: ядро палладия, окруженное родиевой оболочкой.

При этом необходимо отметить, что получение наноматериалов на основе родия сопряжено с определенными трудностями, связанными с кинетической инертностью солей родия. В работе [7] интенсифицировали процесс получения наночастиц Rh-Pd путем применения автоклавных технологий, обладающих в отличие от открытых систем рядом преимуществ: высокой скоростью и глубиной протекания процессов, отсутствием потерь летучих компонентов реакционной смеси, относительной простотой стандартизации условий эксперимента. Установлено, что при контакте высокодисперсного родия с солянокислым раствором хлорида палладия при температуре $180{ }^{\circ} \mathrm{C}$ происходит образование механической смеси индивидуальных компонентов.

Биметаллические системы разнообразны по составу и структуре, что открывает широкие возможности для получения материалов на их основе с улучшенной функциональностью [8]. Такое разнообразие задает огромный горизонт поисковых работ для оптимизации этих систем.

$$
-508-
$$


Однако окончательного ответа на вопрос о влиянии различных факторов на структуру полученных материалов не найдено до сих пор.

Основные подходы к методам химического синтеза таких материалов сводятся к последовательному либо одновременному восстановлению из растворов их комплексных соединений и были нами подробно описаны ранее [9-11].

\section{Экспериментальная часть}

Исходный родий был синтезирован согласно стандартной методике [12]. В работе использовали $\mathrm{PdCl}_{2}$ (х.ч.). Растворы готовили на $1 \mathrm{M} \mathrm{HCl}$, очищенной изотермической перегонкой. Все реакции проводили в среде аргона.

Эксперименты выполнены в разработанных нами кварцевых автоклавах по методике, описанной в [10]. Преимуществами данной конструкции автоклава являются: возможность визуального наблюдения за процессом, разделение компонентов смеси до начала процесса, а также вращение автоклава в вертикальной плоскости, что позволяет осуществить максимальный контакт фаз, что крайне важно при изучении гетерогенных процессов.

Рентгеновские дифракционные данные получены на порошковом дифрактометре PANalytical X'Pert PRO MPD. Микроструктурные характеристики материалов определяли с помощью полнопрофильного анализа рентгенограмм по методу Ритвельда [13].

Содержание комплексных соединений металлов в растворе устанавливали атомноабсорбционным и спектрофотометрическим методами, количество твердой фазы - весовым анализом. Химический состав твердой фазы находили путем растворения навески порошка с последующим анализом на соответствующие элементы на атомно-абсорбционном спектрофотометре марки A Analyst-400 (Perkin Elmer) с электротермическим атомизатором.

Адсорбционные измерения проводили на приборе ASAP 2420 фирмы Micromeritics Instrument Corporation (США) методом низкотемпературной адсорбции азота при 77 К. До начала измерений образцы нагревали до $70{ }^{\circ} \mathrm{C}$ и проводили дегазацию при 1,2 Па. Удельную площадь поверхности рассчитывали по изотермам адсорбции по методу БЭТ.

Микроструктура (размеры и морфология частиц) образцов исследована с помощью просвечивающего электронного микроскопа ПРЭМ200 (при ускоряющем напряжении 100 кВ). Образцы родиевой черни препарировали для электронно-микроскопических исследований путем диспергирования порошка в дистиллированной воде с помощью ультразвукового диспергатора (УЗДНА) в течение 5 мин. После этого полученную взвесь порошка в воде распыляли с помощью ультразвукового диспергатора на коллодиевую пленкуподложку (толщиной 10 нм), высаженную на медную электронно-микроскопическую просмотровую сеточку.

\section{Обсуждение результатов}

По рентгенографическим данным (рис. 1) исходная Rh-чернь состоит из одной кристаллической фазы, имеющей блоки когерентного рассеяния размером 6,2 нм. По данным электронной микроскопии изображение исходного порошка родия свидетельствует о том, что частицы имеют форму, близкую к сферической, и агрегированы между собой в достаточно длинные цепочки, частицы кристаллической фазы имеют размеры около 15 нм (рис. 1). Это позволяет прийти к заключению, что структура исходной родиевой черни близка к моноблочной.

$$
-509-
$$



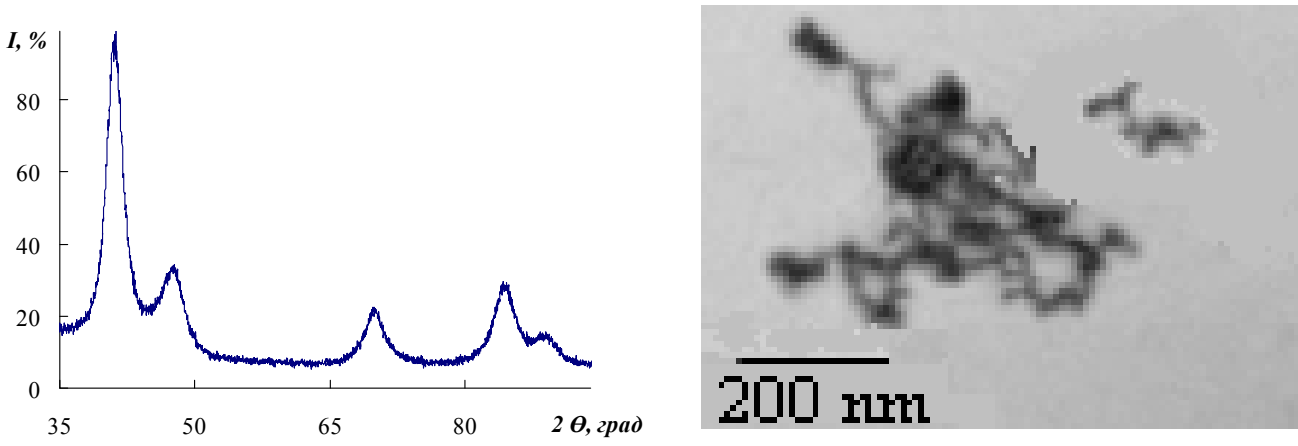

Рис. 1. Исходная родиевая чернь: рентгенограмма и изображение частиц, полученное с помощью электронной микроскопии

Ранее [7] было установлено, что родиевая чернь укрупняется в одноименных растворах соляной кислоты, однако по сравнению с палладием скорость укрупнения родия очень мала [14]. При использовании родия с полиблочной структурой, размеры частиц которого по рентгенографическим данным составляли $60 \AA$, а по данным электронной микроскопии - более $300 \AA$, процессы его укрупнения в солянокислых растворах протекали крайне медленно. После укрупнения при $180{ }^{\circ} \mathrm{C}$ в течение 6 ч размер поверхностных блоков более чем в 1,5 раза превышал размер блоков исходной черни. Значения параметров кристаллической решетки внутренних блоков были близки к значениям этих параметров для исходной черни (размеры внутренних блоков меняются незначительно). Авторы работы [7] объясняют это тем, что если справедлив электрохимический механизм перекристаллизации, подробно описанный в работах [7, 14], то укрупняться должны только соприкасающиеся с раствором поверхностные блоки.

В подтверждение этой гипотезы в настоящей работе исследовали процессы укрупнения родия, имеющего моноблочную структуру. Результаты исследования показали значительное увеличение скорости укрупнения родия: при контакте родиевой черни с раствором $\mathrm{RhCl}_{3}$ в $1 \mathrm{M}$ соляной кислоте при $180{ }^{\circ} \mathrm{C}$ укрупнение происходит до 11,6 нм, а при $130{ }^{\circ} \mathrm{C}$ - до 8 нм.

В ходе данной работы было установлено, что при температуре $130{ }^{\circ} \mathrm{C}$ одновременно с укрупнением наблюдается растворение родия. Окислительным агентом в рассматриваемом случае может быть кислород, содержащийся в газовой фазе, растворенный в объеме раствора и (или) адсорбированный на поверхности родия. При этом, вне зависимости от источника кислорода, процесс растворения описывается следующим уравнением реакции:

$$
4 \mathrm{Rh}+3 \mathrm{O}_{2}+24 \mathrm{HCl}=4 \mathrm{H}_{3} \mathrm{RhCl}_{6}+6 \mathrm{H}_{2} \mathrm{O} .
$$

Растворение заканчивается в течение 15 мин после приведения черни в контакт с соляной кислотой.

Количество растворившегося металла определяли по убыли массы, атомно-адсорбционным и спектрофотометрическим анализами. Отсутствие потерь мелкодисперсного металла при отделении осадка от раствора подтверждалось сходимостью определения количества металла независимыми методами в пределах $2 \%$. Максимальное количество моль кислорода, находящегося в газовой и жидкой фазах, равно 2,74·10-4 моль; причем количество кислорода в газовой

$$
-510-
$$


фазе примерно в шесть $(5,7)$ раз больше, чем в растворе при стандартной степени заполнения автоклава. Для исключения из рассмотрения растворения родия кислородом газовой фазы или растворенным в растворе осуществляли его тщательное удаление барботированием аргона через систему. Изменения объема газовой фазы и объема раствора не приводили к изменению процента растворимости при той же температуре, что указывает на то, что используемая в настоящей работе методика удаления кислорода воздуха вполне приемлема, и в соляной кислоте отсутствовали примеси, способные окислять металл. Таким образом, основной причиной растворения родиевой черни является наличие на ее поверхности кислорода. В таблице представлены результаты исследований растворения высокодисперсных порошков Rh в $1 \mathrm{M}$ соляной кислоте при температурах 130 и $180{ }^{\circ} \mathrm{C}$.

При данных температурах исследования шли в кварцевых автоклавах, из газовой и жидкой фаз которых предварительно удаляли кислород путем барботирования аргоном, тем самым добиваясь исключения реакции (1). Таким образом, растворение металла проходило без доступа воздуха. Процессы частичного растворения мелкодисперсного родия протекают с достаточно большой скоростью и заканчиваются за 15 мин. При увеличении времени обработки до 1 ч доля растворенного металла практически не изменяется.

Растворение родия происходит за счет хемсорбированного кислорода на поверхности металла. Зависимость концентрации родия в растворе $\left(C_{\mathrm{Rh}(I I I)}\right)$ от количества кислорода $(\alpha)$, адсорбированного на единице площади, описывается формулой

$$
4 / 3 C_{\mathrm{Rh}(I I I)} V=6 \alpha m_{0} / d \rho,
$$

где $\rho$ - плотность металлического родия.

На рис. 2 представлена зависимость числа молей $\mathrm{n}$ трехвалентного родия в растворе (растворившегося) от отношения навески к диаметру частиц $\mathrm{m}_{\mathrm{o}} / \mathrm{d}$. Данная зависимость подчиняется линейному уравнению (2).

На основании формулы (2) и данных, представленных на рис. 2, было рассчитано количество кислорода, адсорбированного на единице площади палладия $\alpha=1,55 \cdot 10^{-5}$ моль $/ \mathrm{M}^{2}$, которое удовлетворительно согласуется с данными работы [15] $\alpha=9,5 \cdot 10^{-6}$ моль $/ \mathrm{M}^{2}$.

Исходя из значений, приведенных на рис. 2, было рассчитано число молекул кислорода $\mathrm{n}_{\mathrm{O} 2}=9 \cdot 10^{19}$ на $1 \mathrm{~m}^{2}$ поверхности, а также площадь, занимаемая молекулой кислорода $\mathrm{S}_{\mathrm{O} 2}=5 \cdot 10^{-20} \mathrm{M}^{2}$.

Таблица. Растворение высокодисперсных порошков родия в $1 \mathrm{M}$ соляной кислоте при температурах 130 и $180{ }^{\circ} \mathrm{C}$ в течение 1 ч

\begin{tabular}{|c|c|c|c|c|}
\hline $\begin{array}{c}\text { Масса родия } \\
m_{0}, \text { мг }\end{array}$ & $\begin{array}{c}\text { Объем раствора } \\
V, \text { мл }\end{array}$ & $\begin{array}{c}\text { Размер частиц } \\
d, \AA\end{array}$ & $\begin{array}{c}\text { Температура } \\
t,{ }^{\circ} \mathrm{C}\end{array}$ & $\begin{array}{c}\text { Степень растворения } \\
\beta, \%\end{array}$ \\
\hline 186,30 & 20 & 62 & 130 & 8,2 \\
\hline 96,60 & 29 & 62 & 180 & 11,5 \\
\hline 99,50 & 29 & 62 & 130 & 11,3 \\
\hline 490,10 & 29 & 62 & 130 & 9,2 \\
\hline 93,35 & 29 & 80 & 130 & 4,7 \\
\hline 74,20 & 29 & 112 & 130 & 3,1 \\
\hline
\end{tabular}




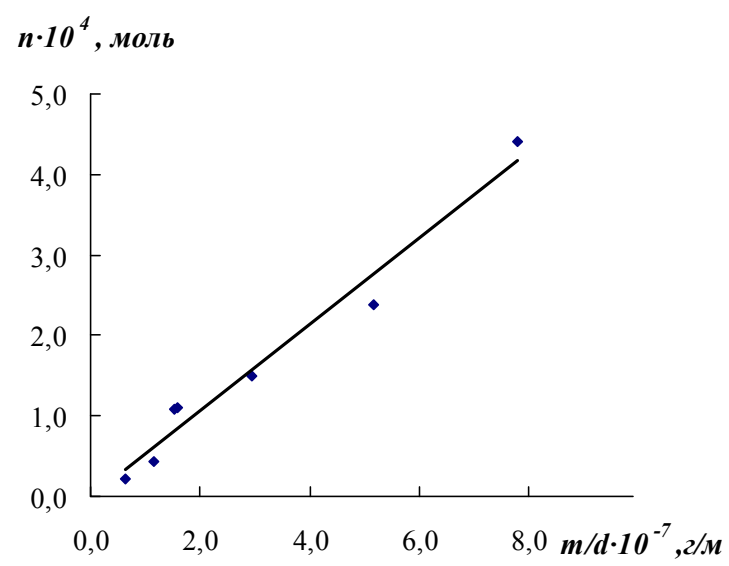

Рис. 2. Зависимость числа молей $n$ трехвалентного родия в растворе от отношения навески к диаметру частиц $m_{0} / d$

Последнее значение неплохо согласуется с данными работы [16], где приведена площадь одного центра адсорбции кислорода $\sigma^{0}=10^{-19} \mathrm{M}^{2}$ для никеля.

Взаимодействие высокодисперсного родия с раствором хлорида палладия протекает по уравнению реакции (3)

$$
3 P d^{2+}+2 R h^{0}=3 P d^{0}+2 R h^{3+}, \quad \Delta \mathrm{G}=-147 \text { кДж. }
$$

Диаграмма состояния Rh-Pd представляет собой неограниченный ряд твердых растворов, однако ранее [7] было установлено, что при использовании родия с полиблочной структурой процесс контактного восстановления палладия при температуре $180{ }^{\circ} \mathrm{C}$ заканчивается в течение нескольких часов и вызавает образование механической смеси двух металлов.

Нами установлено, что при мольном соотношении $\mathrm{Rh} / \mathrm{Pd}$, равном 2 , и температуре $130{ }^{\circ} \mathrm{C}$ процесс контактного восстановления палладия родием, имеющим моноблочную структуру, заканчивается в течение 90 мин, дальнейшее увеличение времени эксперимента не изменяет концентраций родия и палладия в растворе. Уже спустя 30 минут от начала эксперимента по данным масс-спектрометрического анализа из раствора восстанавливается около 45 \% палладия, а к концу процесса степень его восстановления достигает 70 \%.

Согласно данным газовой адсорбции в результате реакции происходит уменьшение площади поверхности полученных порошков. Так, спустя 30, 90 и 120 мин удельная площадь равна $57,1,44,15$ и 29,4 м²/г соответственно. Изменение удельной поверхности частиц после окончания контактного восстановления можно объяснить процессами электрохимической перекристаллизации палладия, которые приводят к значительному укрупнению частиц.

По данным РФА в результате протекания реакции (3) зафиксировано образование твердого (Rh, Pd) раствора замещения.

\section{Выводы}

1. Установлена значительная роль хемисорбированного кислорода в процессах растворения нанодисперсного родия в растворах соляной кислоты при повышенных температурах. 
2. Впервые было обнаружено образование твердого раствора замещения при цементации палладия родием, имеющим моноблочную структуру.

3. Установлено, что при взаимодействии высокодисперсного порошка родия с солянокислым раствором хлорида палладия (II) решающую роль в образовании твердого раствора или механической смеси играет структура металла-восстановителя.

Авторы благодарят С.М. Жаркова за проведение электронно-микроскопических исследований и В.А. Парфенова за измерения удельных поверхностей.

\section{Список литературы}

[1] Araya, P., Diaz A.V. // Faraday Trans. 1997. № 93. P. 38-87.

[2] Dehm N. A., Zhang X., Buriak J. M. // Inorg. Chem. 2010. № 49. P. 27-06.

[3] Yoon B., Pan H-B., Wai Ch. M. // J. Phys. Chem. 2009. № 113. P. 15-20.

[4] Massalski T. B., Okamoto H., Subramanian P. R. and L. Kacprzak (ed.) // Binary Alloy Phase Diagrams 2-nd ed., ASM International, Materials Park, Ohio. 1990. P. 17-51.

[5] Коренев С.В., Шубин Ю.В., Беляев А.В. // ЖНХ. 2001. № 1. С. 70.

[6] Tao F., Grass M.E., Zhang Y. et al // J. Am. Chem. Soc. 2010, № 132, P. 86-97.

[7] Коваленко Н.Л., Белоусов О.В., Дорохова Л.И. и др. // ЖНХ. 1995. № 4. С. 678.

[8] Grass M. E., Park M., Aksoy F. et al // Langmuir. 2010. № 21. P. 16362.

[9] Belousov O., Belousova N., Burlo A. // Smart Nanocomposites. 2010.1. № 1. P. 91.

[10] Belousov O., Belousova N., Sirotina A. et al // Langmuir. 2011. 18. P. 11697.

[11] Белоусова Н.В., Сиротина А.В., Белоусов О.В. и др. // ЖНХ. 2012. № 1. С. 18.

[12] Коваленко Н.Л., Дорохова Л.И. // ЖНХ 1991. № 10. С. $25-71$.

[13] Rietveld H.M. // J. Appl. Cryst. 1969. 2. P. 65.

[14] Белоусов О.В., Дорохова Л.И., Соловьев Л.А. и др. // ЖФХ. 2007. № 8. С. 14-79.

[15] Буянова Н.E. Определение поверхности и дисперсности нанесенных металлов восьмой группы хемосорбционными методами. М.: Наука, 1976. 137 с.

[16] Адамсон А. Физическая химия поверхностей. М: Мир, 1979. 586 с. 